\title{
Analysis of Studies on Social Support and Children of Depressed Mothers: A Systematic Review
}

\author{
Ana Paula Casagrande Silva ${ }^{1}$ \\ Universidade de São Paulo, Ribeirão \\ Preto-SP, Brazil
}

\author{
Sonia Regina Loureiro \\ Universidade de São Paulo, Ribeirão \\ Preto-SP, Brazil
}

\begin{abstract}
Recognizing the conditions that minimize the impact of maternal depression on children has clinical relevance. The present review aimed to analyze recent empirical studies that have investigated the associations between maternal depression and different social support conditions for school-aged children. We systematically reviewed empirical articles indexed from 2007 to 2014 in the following databases: MEDLINE, PubMed, PsycINFO, Web of Science, LILACS and SciELO. Three keywords were used: maternal depression, social support and child behavior. Twenty-seven articles were included and analyzed. These studies included a broad range of contextual risk factors and social support conditions, and in their predictive models, it was found that less contextual risk and greater parental resources and social support were predictors of fewer problems for the children. The identification of social support sources that attenuate the effect of maternal depression on child outcomes has implications for the development of prevention and intervention programs.
\end{abstract}

Keywords: depression, mothers, child psychology, psychosocial factors, literature review

\section{Análise de Estudos Sobre Suporte Social e Filhos de Mães Deprimidas: Uma Revisão Sistemática}

\begin{abstract}
Resumo: Reconhecer condições que minimizem o impacto da depressão materna para as crianças tem relevância clínica. Objetivou-se analisar estudos empíricos recentes que investigaram as associações da depressão materna a condições de suporte social. Procedeu-se a revisão sistemática de artigos indexados no período de 2007 a 2014 nas bases de dados MEDLINE, PubMed, PsycINFO, Web of Science, LILACS e SciELO, utilizando-se as palavras-chave: maternal depression, social support e child behavior. Foram incluídos e analisados 27 artigos. Os estudos analisados incluíram uma ampla diversidade de condições de risco e de fontes de suporte social, e nos modelos preditivos utilizados, constatou-se que menos risco contextual, mais recursos parentais e suporte social foram preditores de menos problemas para as crianças. O suporte social atenuou o impacto da depressão maternal para os desfechos das crianças, o que tem implicações para o planejamento de programas de prevenção e intervenção.
\end{abstract}

Palavras-chave: depressão, mães, psicologia da criança, fatores psicossociais, revisão de literatura

\section{Soporte Social y los Infantes de Madres con Depresión: Una Revisión Sistemática}

\begin{abstract}
Resumen: Reconocer condiciones que minimicen el impacto de la depresión maternal para los niños tiene relevancia clínica. Se objetivó analizar estudios empíricos recientes que investigaron las asociaciones de la depresión materna a condiciones diversas del soporte social. Se realizó una revisión sistemática de artículos empíricos indexados en el período de 2007 a 2014 en MEDLINE, PubMed, PsycINFO, Web of Science, LILACS y SciELO, utilizando las palabras clave: maternal depression, social suport y child behavior. Fueron incluidos y analizados 27 artículos. Los estudios revisados incluyeron una amplia variedad de condiciones de riesgo y fuentes de soporte social, y en los modelos predictivos utilizados, se constató que menos riesgo contextual, más recursos parentales y soporte social fueran predictores de menos problemas para los niños. El soporte social atenúo el impacto de la depresión maternal para los desenlaces de los niños lo que tiene implicaciones para la planificación de programas de prevención e intervención.
\end{abstract}

Palabras clave: depresión, madres, psicología infantil, factores psicosociales, revisión de literatura

Throughout development, children are exposed to numerous contextual risk factors and adverse conditions, including maternal depression. This contextual condition is associated with childhood problems because it negatively affects child development, thereby potentiating behavioral and

\footnotetext{
Correspondence address:

Ana Paula Casagrande Silva. Faculdade de Medicina de Ribeirão Preto, Universidade de São Paulo. Avenida Tenente Catão Roxo, 2650. Vila Monte Alegre. CEP 14051-140. Ribeirão Preto-SP, Brazil. E-mail: anapaulacasagrande@usp.br
}

emotional difficulties. Child exposure to maternal depression is associated with a greater frequency of both externalizing and internalizing symptoms, a greater incidence of psychiatric disorders, and lower social competence (Goodman et al., 2011).

Mendes, Loureiro, and Crippa (2008) conducted literature reviews and reported that familial conditions, such as reductions in social support, parental care practices, environmental organization, socioeconomic status, and social support networks, are associated with maternal depression. The presence of maternal depression determines whether 
these associations are contextual risk or protective factors that influence behavioral outcomes in children. Elgar, Mills, McGrath, Waschbusch, and Brownridge's (2007) literature review suggested that depressive symptoms were predictive of low parental nurturance and poor monitoring of the child's activities, as well as greater rejection of the child, increasing the impact of parental psychopathology on child functioning.

In a meta-analysis, Goodman et al. (2011) stated that, despite the wide acceptance of the negative effects of maternal depression on child development, the field still lacks studies on the contextual risk factors (e.g., the conditions associated with maternal depression) that might influence child outcomes. One of these variables is social support, which has been considered a protective factor in individuals exposed to stressful events and may therefore moderate the effects of maternal depression on child adjustment.

Social support is defined by Gottlieb (1983) as "verbal and non-verbal information or advice, tangible aid, or action that is proffered by social intimates or inferred by their presence and has beneficial emotional or behavioral effects on the recipients" (p. 28). From this perspective, social support encompasses multiple dimensions, including instrumental, emotional, informational, and tangible aid, as well as positive social interaction, affection, and esteem; it is also transactional - that is, it is affected by the nature of the stress factors and personal traits.

Considering the clinical relevance of recognizing the impact of social support for children who coexist with maternal depression, approaching the state of the art on this subject is justified. The present review sought to identify and analyze recent empirical studies investigating the associations between maternal depression and different social support conditions, focusing on the effects in school-age children.

\section{Method}

A systematic review of the literature was performed via a search of scientific articles published from 2007 to 2014 and abstracted in the following electronic databases: MEDLINE, PubMed, PsycINFO, Web of Science, LILACS (Literatura Latino-Americana e do Caribe em Ciências da Saúde [Latin American and Caribbean Health Science Literature]), and SciELO (Scientific Electronic Library Online). We used the following keywords: maternal depression, social support, and child behavior.

As inclusion criteria for the search, we used language (Portuguese, English, or Spanish) and the moment of evaluation (i.e., the child and his or her mother were evaluated at least once during the school years between six and 12 years of age, regardless of whether there were additional assessments before or after this period). Studies were excluded if they focused exclusively descriptions of programs involving institutional social support and interventions with specific at-risk populations or other age groups.

The empirical article search mentioned above was performed using different combinations of keywords (three at the same time or two by two). Then, 1,467 articles were identified in the search of electronic databases, and the inclusion and exclusion criteria were applied. The abstracts of the 241 papers identified in the search were systematically read. Based on this reading, 213 articles were excluded from the analyses. The remaining 27 papers, which met all the criteria, were selected and analyzed after full reading.

The content of the papers were then categorized with regard to study design, contextual risk factors, social support conditions, and major outcomes concerning the impact of social support on the behavior of children exposed to maternal depression. The methodological quality of the studies was evaluated using the Newcastle-Ottawa Scale (NOS). The data were independently extracted and categorized by the two authors, and any discrepancies between the authors were discussed and resolved in a consensus meeting. This categorization is described in the following section.

\section{Results}

Data regarding our analysis are introduced by initially emphasizing the general characteristics of the samples, the designs and instruments used, and the contextual risk factors and social support conditions. Next, the major outcomes from these studies are listed based on their cross-sectional and longitudinal designs; correlational or experimental studies are specified with regard to the latter design.

Regarding the evaluation of the methodological quality of the articles, it was found that none of the cross-sectional studies (8) had a case-control design; therefore, it was not possible to evaluate these articles through the NOS. Of the longitudinal studies (19), 12 were cohort studies, to which it was possible to apply the NOS criteria. Regarding the maximum possible rating (eight stars), it was verified that seven articles received excellent ratings (seven to eight stars) and five articles received sufficiently positive ratings (five to six stars). The representativity of the cohort, the specification of the inclusion and exclusion criteria for the participants exposed and not exposed to the problem, the use of validated instruments, and the adequacy of the follow-up were the main issues in evaluating the studies.

Twenty-seven studies were included in the present review, which included 29,903 dyads of participants. The sample size varied from 40 to 7,429 dyads with a median of 2,945 dyads. Most studies $(23 ; 85.18 \%)$ were performed using community samples, and the samples used in five studies $(18.51 \%)$ were considered high risk because they were mainly composed of low-income families (AllenMeares, Blazevski, Bybee, \& Oyserman, 2010; Criss, Shaw, Moilanen, Hitchings, \& Ingoldsby, 2009; Fatori, Bordin, Curto, \& de Paula, 2013; Goosby, 2007; Mickelson \& Demmings, 2009). Most of the participants in the studies were White Caucasian, and the studies were conducted in the following countries: USA (16), UK (3), Brazil (3), India (2), Canada (2), Norway (1) and Finland (1). Most of the studies examined males and females, except for three studies that 
only included boys (Brown, Barbarin, \& Scott, 2013; Criss et al., 2009; Gross, Shaw, Burwell, \& Nagin, 2009).

With regard to study design, there were eight correlational cross-sectional studies (29.62\%) and 19 longitudinal studies (70.37\%); of the latter, five were correlational, and 14 were experimental. Overall, the longitudinal studies had, on average, four to six evaluations over the follow-up, including periods of 3 months to 13 years.

Three cross-sectional studies included young childhood to adolescents (Gerkensmeyer, Perkins, Day, et al., 2011; Gerkensmeyer, Perkins, Scott, \& Wu, 2008; Mickelson \& Demmings, 2009). Most longitudinal studies monitored young children; among these studies, five focused on the behavior of children from 6 to 7.5 years old (Anhalt, Telzrow, \& Brown, 2007; Ashman, Dawson, \& Panagiotides, 2008; Barker, Copeland, Maughan, Jaffee, \& Uher, 2012; Campbell, Matestic, von Stauffenberg, Mohan, \& Kirchner, 2007; Heberle, Krill, Briggs-Gowan, \& Carter, 2014), and the other six studies examined 12- to 13-year-old children (Barker \& Maughan, 2009; Criss et al., 2009; Fatori et al., 2013; Gross et al., 2009; Hart, Atkins, \& Matsuba, 2008; Karevold, Roysamb, Ystrom, \& Mathiesen, 2009).
Most of the cross-sectional $(7 ; 87.5 \%)$ and longitudinal studies $(16 ; 84.21 \%)$ used instruments adapted and validated to measure maternal depression and childhood behavioral problems, psychopathologies, or both. In addition, five crosssectional (62.5\%) and eight longitudinal (42.1\%) studies used instruments adapted and validated as social support assessment resources. The Center for Epidemiological Studies Depression Scale (CES-D) and the Child Behavior Checklist (CBCL) were the most commonly used instruments to assess maternal depression symptoms $(12 ; 44.44 \%)$ and child behavioral problems $(15 ; 55.55 \%)$. A broad variety of social support instruments and procedures were used. The most frequently used measures were questionnaires developed by the authors $(11 ; 40.74 \%)$, the Home Observation for Measurement of the Environment (HOME; 4; 14.81\%), and other scales $(5 ; 18.51 \%)$. In addition, four studies assessed social support via observations of mother-child interactions (Campbell et al., 2007; Dubois-Comtois, Moss, Cyr, \& Pascuzzo, 2013; Gross et al., 2009; Wang, Christ, MilssKoonce, Garrett-Peters, \& Cox, 2013).

All studies included in the present review addressed contextual risk factors and social support conditions (Table 1).

Table 1

Contextual Risk Factors and Social Support Conditions

\begin{tabular}{|c|c|c|}
\hline \multirow[t]{2}{*}{ Contextual Risk Factors } & \multicolumn{2}{|c|}{ Social Support } \\
\hline & $\begin{array}{l}\text { Environmental, Family, and Neighborhood } \\
\text { Resources }\end{array}$ & Parental Resources \\
\hline Maternal Clinical Conditions $(n=16)$ & $2,3,5,6,12,14,15,16,17,20,23,24$ & $1,6,12,18,21,22$ \\
\hline Low Socioeconomic Status $(n=14)$ & $2,4,5,6,10,12,13,14,15,16,17,18,20$ & $6,10,11,12,16$ \\
\hline Negative Parental Practices $(n=12)$ & $5,9,10,13,15,18,20,25$ & $7,8,9,10,18,21,26$ \\
\hline Family Conflicts $(n=10)$ & $4,5,6,15,17,18,19,20,22,23$ & 6,18 \\
\hline Low Maternal Educational Level $(n=8)$ & $2,4,5,6,13,16,20$ & 6,18 \\
\hline One-Parent Family $(n=6)$ & $4,13,15$ & $1,11,18$ \\
\hline High-Risk Neighborhood $(n=3)$ & 16,27 & 7 \\
\hline \multicolumn{3}{|c|}{ 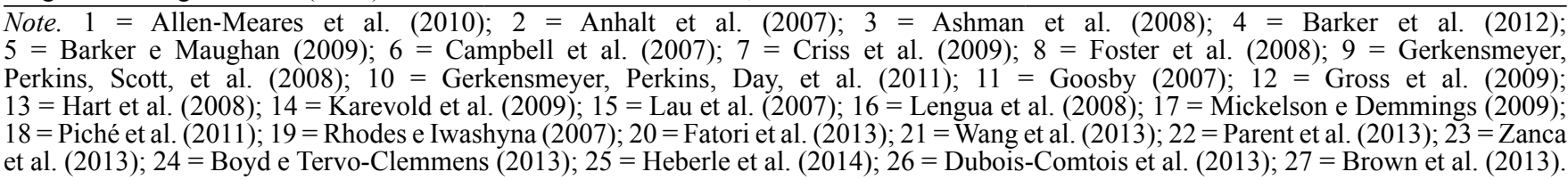 } \\
\hline
\end{tabular}

These studies addressed contextual risk factors across different domains. The most commonly studied variables (in order) were maternal clinical conditions, low economic status and negative parental practices.

The trajectories of maternal depression with regard to severity and chronicity (Ashman et al., 2008; Campbell et al., 2007; Fatori et al., 2013; Gross et al., 2009; Parent, Jones, Forehand, Cuellar, \& Shoulberg, 2013; Wang et al., 2013; Zanca, Pizeta, Osório, \& Loureiro, 2013) and the presence of comorbidities, especially those related to anxiety (Barker \& Maughan, 2009; Boyd \& Tervo-Clemmens, 2013; Fatori et al., 2013; Karevold et al., 2009; Lau, Rijsdijk, Gregory, McGuffin, \& Eley, 2007; Mickelson \& Demmings, 2009;
Piché, Bergeron, Cyr, \& Berthiaume, 2011), were identified as contextual risk factors for maternal clinical conditions. Twelve studies addressed negative parental practices including negligence, physical and psychological abuse, lax discipline, inconsistent punishment, and negative monitoring. Five of these studies focused on negligence (Criss et al., 2009; Foster et al., 2008; Gerkensmeyer, Perkins, Day, et al., 2011; Gerkensmeyer, Perkins, Scott, et al., 2008; Hart et al., 2008), four focused on punishment (Barker \& Maughan, 2009; Fatori et al., 2013; Piché et al., 2011; Wang et al., 2013), and one focused on abuse (Piché et al., 2011). Most of the studies assessed at least two contextual risk factors, and all studies examined between one and five variables. 
The present review categorized social support conditions into two major groups: (1) environmental, family, and neighborhood resources; and (2) parental resources. Environmental, family, and neighborhood resources included conditions related to few stressors, social support from relationships with people in general, and the availability of community services. Parental resources included the following: (a) conditions related to positive parental practices and (b) maternal mental health resources. Most of the articles evaluated social support conditions with regard to environmental, family and neighborhood resources.

The present review identified eight cross-sectional studies that addressed maternal depression and its relationship to social support. Table 2 shows the major outcomes.
Of the eight cross-sectional studies, seven found that more social support was significantly associated with fewer problems among children exposed to maternal depression. Five studies also identified associations with the presence of fewer risk variables.

Only one study (Piché et al., 2011) did not find correlations among social support, maternal depression, and child behavioral problems, psychopathologies or both; however, this study addressed many clinical, social, and familial variables. These authors reported that the contextual risk factors related to negative parental practices expressed by fewer maternal punishments were associated with fewer externalizing behavioral problems in children.

Table 2

Cross-Sectional Studies: Associations Between Social Support and Risks $(n=8)$

\begin{tabular}{|c|c|}
\hline \multirow{2}{*}{ Study } & Major Outcomes \\
\hline & Significant Associations Between Social Support and Risks for Children \\
\hline 9 & $\begin{array}{c}\text { Present } \\
\uparrow \text { Social support } \downarrow \text { Parental depression } \downarrow \text { Behavioral problems }\end{array}$ \\
\hline 10 & $\begin{array}{c}\text { Present } \\
\uparrow \text { Social support } \downarrow \text { Maternal depression } \downarrow \text { Behavioral problems }\end{array}$ \\
\hline 17 & $\begin{array}{c}\text { Present } \\
\uparrow \text { Social support } \downarrow \text { Child depression }\end{array}$ \\
\hline 18 & Absent \\
\hline 19 & $\begin{array}{l}\text { Present } \\
\uparrow \text { Social support } \downarrow \text { Home insecurity } \downarrow \text { Children at risk of accidents } \\
\uparrow \text { Social support } \downarrow \text { Marital conflicts } \downarrow \text { Children at risk of accidents }\end{array}$ \\
\hline 22 & $\begin{array}{c}\text { Present } \\
\uparrow \text { Social support } \downarrow \text { Behavioral problems }\end{array}$ \\
\hline 23 & $\begin{array}{c}\text { Present } \\
\uparrow \text { Social support } \downarrow \text { Behavioral problems } \\
\uparrow \text { Social support } \downarrow \text { Chronic adversity } \downarrow \text { Behavioral problems }\end{array}$ \\
\hline 24 & $\begin{array}{c}\text { Present } \\
\uparrow \text { Social support } \downarrow \text { Maternal comorbid anxiety disorders } \downarrow \text { Behavioral problems }\end{array}$ \\
\hline
\end{tabular}

Note. $\uparrow=$ More; $\downarrow=$ Less; $9=$ Gerkensmeyer, Perkins, Scott, et al. (2008); $10=$ Gerkensmeyer, Perkins, Day, et al. (2011); $17=$ Mickelson e Demmings (2009); 18 = Piché et al. (2011); 19 = Rhodes e Iwashyna (2007); 22 = Parent et al. (2013); 23 = Zanca et al. (2013); 24 = Boyd e Tervo-Clemmens (2013).

Of the 19 longitudinal studies examined, five adopted a correlational design that addressed maternal depression and its association with social support. Table 3 shows the major outcomes.

Four of these five studies reported that more social support was correlated with fewer externalizing and/or internalizing behavioral problems. Campbell et al. (2007) highlighted the relevancy of greater maternal sensitivity in her interactions with her child, including expressions of positive respect, low intrusiveness, greater supportive presence, more respect to autonomy, and low hostility.

Another study found that more social support was correlated with fewer internalizing behavioral problems by studying these variables in the context of positive maternal response to pharmacological treatments (i.e., the remission of maternal depressive symptoms) (Foster et al., 2008).
Only one study (Fatori et al., 2013) failed to find an association between social support and the aggravation of child and adolescent mental health problems at a later assessment. The authors suggest that this finding might be due to the presence of severe physical abuse over an extended period of time, highlighting the deleterious effects of chronic violence.

Of the 19 longitudinal studies, 14 adopted experimental designs and addressed the variables that predicted fewer problems among children. Table 4 shows the major outcomes. Of the 14 studies analyzed, only one did not find social support to be a predictor of fewer behavioral problems and/or psychopathology.

Eight of the nine studies that assessed behaviors revealed that social support predicted fewer behavioral problems. Variables such as greater paternal involvement, more informal 
Table 3

Longitudinal Correlational Studies: Associations Between Social Support and Risks $(n=5)$

\begin{tabular}{|c|c|}
\hline \multirow{2}{*}{ Study } & Major Outcomes \\
\hline & Significant Associations Between Social Support and Risks for Children \\
\hline 2 & $\begin{array}{l}\text { Present } \\
\uparrow \text { Social support }(1 \text { month old }) \downarrow \text { E }(6 / 7 \text { years old }) \\
\downarrow \text { Stressor events }(1 \text { month old }) \downarrow \text { I }(6 / 7 \text { years old })\end{array}$ \\
\hline 4 & $\begin{array}{c}\text { Present } \\
\uparrow \text { Social support } \downarrow E \downarrow I\end{array}$ \\
\hline 6 & $\begin{array}{l}\text { Present } \\
\text { Severe/chronic MD trajectory } \uparrow \text { Social support }(1 \text { month old to } 7 \text { years old }) \downarrow E \text { ( } 7 \text { years old })\end{array}$ \\
\hline 8 & $\begin{array}{c}\text { Present } \\
\text { MD remission post-treatment } \uparrow \text { Social support } \downarrow \text { I } \\
\downarrow \text { Conflicting stressors } \downarrow \text { I }\end{array}$ \\
\hline 20 & Absent \\
\hline
\end{tabular}

$\overline{\text { Note. } \uparrow} \uparrow=$ More; $\downarrow=$ Less; E = Externalizing; I = Internalizing; MD = Maternal Depression; 2 = Anhalt et al. (2007); $4=$ Barker et al. (2012); $6=$ Campbell et al. (2007); $8=$ Foster et al. (2008); $20=$ Fatori et al. (2013).

Table 4

Longitudinal Experimental Studies: Social Support and Outcomes in Children $(n=14)$

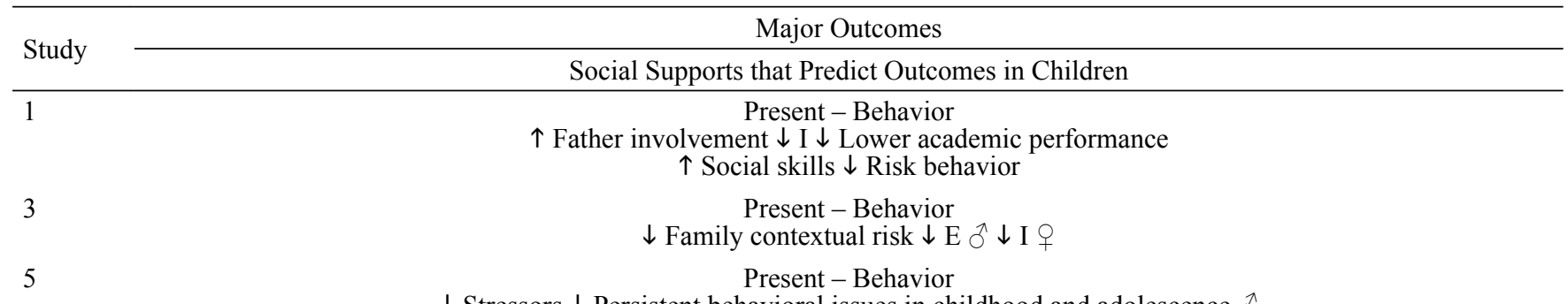

$\downarrow$ Stressors $\downarrow$ Persistent behavioral issues in childhood and adolescence $\sigma^{\lambda}$ $\uparrow$ Social support for mothers $\downarrow$ Persistent behavioral issues in children and adolescents $ᄋ$

11

Note. $\uparrow=$ More; $\downarrow=$ Less; $\mathrm{E}=$ Externalizing; I = Internalizing; MD = Maternal Depression; 1 = Allen-Meares et al. (2010); $3=$ Ashman et al. (2008); 5 = Barker e Maughan (2009); 7 = Criss et al. (2009); $11=$ Goosby (2007); 12 = Gross et al. (2009); $13=$ Hart et al. (2008); $14=$ Karevold et al. (2009); $15=$ Lau et al. (2007); $16=$ Lengua et al. (2008); $21=$ Wang et al. (2013); 25= Heberle et al. (2014); $26=$ Dubois-Comtois et al. (2013); $27=$ Brown et al. (2013).

Present - Behavior and Psychopathology Continuous exposure to poverty $\uparrow$ Parental resources (i.e., perception of mother's control) $\downarrow$ Behavioral Problems $\downarrow$

Depression and anxiety in adolescence

Present - Behavior and Psychopathology
Mild MD trajectory $\downarrow E \downarrow$ Delinquency in adolescence $\curvearrowright$

Present - Behavior

Low poverty neighborhood $\downarrow$ Behavioral problems over 2 years old $\uparrow$ Maternal educational level $\uparrow$ Social support $\downarrow$ Unstable personality profiles

Present - Behavior and Psychopathology

$\downarrow$ Family adversity $\downarrow$ Child depression

$\uparrow$ Social support for mothers of timid $q \downarrow$ I

Present - Psychopathology

$\downarrow$ Negative locus of control $\downarrow$ Punitive parental discipline $\downarrow$ Children with depressive symptoms

$\downarrow$ Negative locus of control $\downarrow$ Negative events $\downarrow$ Children with depressive symptoms

$\uparrow$ Children's self-control $\downarrow$ Maternal risk $\downarrow$ I $\uparrow$ Children's self-control $\downarrow$ Environmental risk $\downarrow$ I $\downarrow$ E

Present - Behavior

$\uparrow$ Maternal harshness $\uparrow \mathrm{E}$

Present - Behavior

$\uparrow$ Informal social support $\downarrow$ Maternal psychological distress $\downarrow$ Suboptimal parenting behavior $\downarrow$ I

Present - Behavior

$\downarrow$ Maternal psychosocial distress and controlling attachment patterns $\downarrow$ I $\downarrow$ E

$\downarrow$ Maternal psychosocial distress $\uparrow$ Quality of mother-child interactions $\downarrow$ I $\downarrow$ E

Absent - Behavior

$$
\text { Present - Psychopathology }
$$

High-risk neighborhood $\uparrow$ Social support $\downarrow$ Antisocial behaviors in adolescents $\widehat{\sigma}$ 
social support, more maternal social support, less maternal risk (teenage motherhood, legal problems and maternal mental health), low levels of poverty, fewer environmental risks, fewer contextual risk factors, fewer controlling patterns (punitive or caregiving) and a higher quality of mother-child interactions in association with maternal depression were predictors of fewer behavioral problems.

While Brown et al. (2013) verified that family support did not present a predictive effect in relation to the internalizing problems of black boys, they highlighted that increased early cognitive skills predict lower initial levels of internalizing problems.

Five studies found that social support predicted fewer psychopathologies in children and adolescents exposed to maternal depression. In these studies, less familial adversity, fewer stressors and less parental punitive discipline, and more parental resources when faced with continuous exposure to poverty in association with maternal depression were predictors of less psychopathology.

\section{Discussion}

The present review suggests that different types of social support may reduce behavioral problems and the risk for psychopathology in children exposed to maternal depression. These studies used different definitions and instruments to assess social support, including standardized instruments, questionnaires developed by the authors, observations of mother-child interactions, and indirect assessments to verify the infrequent occurrence of stressors within families. Therefore, it was not possible to identify a "gold standard" social support assessment from any of the studies included in the present review. Accordingly, Rueger, Malecki, and Demaray (2010) indicated that the differences in the strategies used to measure social support in the studies may lead to different results and may prejudice the comparison of the results.

The analysis of the studies verified the absence of an unequivocal definition for support, given the diversity of instruments used for its evaluation, and little explanation related to the source of support and whether this support was perceived or actually received. An explanation of these points may provide greater clarity on this subject.

Given this diversity of measurements and the fact that the abovementioned authors addressed a broad set of heterogeneous conditions, generalizing the findings regarding the positive effect of social support is difficult. To understand this diversity, the present study used broad conditions to categorize the types of social support: (a) environmental, family, and neighborhood resources; and (b) parental resources.

Importantly, the broad combination of contextual risk factors domains and diverse conditions also hinders data comparison. This difficulty is inherent to the study of maternal depression, which is related to a wide variety of stressors and cumulative risk, the latter of which can increase the likelihood of negative child outcomes. Maternal clinical conditions (chronicity of maternal depression), low economic status (poverty) and negative parental practices were the most frequently assessed contextual risk factors, regardless of the type of child outcome assessed, in the analyzed studies.

Importantly, seven studies (25.92\%) (Ashman et al., 2008; Barker et al., 2012; Barker \& Maughan, 2009; Gross et al., 2009; Lau et al., 2007; Lengua, Bush, Long, Kovacs, \& Trancik, 2008; Zanca et al., 2013) have considered the frequency or number of contextual risk factors as social support, referring to the presence of fewer stressors and negative conditions in family life or the surrounding environment. This finding indicates that the operational definitions of social support require additional delimitation.

Most of the selected studies used instruments to screen for maternal depressive symptoms. Only four studies (AllenMeares et al., 2010; Ashman et al., 2008; Boyd \& TervoClemmens, 2013; Zanca et al., 2013) conducted a diagnostic evaluation. Four studies (Ashman et al., 2008; Campbell et al., 2007; Gross et al., 2009; Fatori et al., 2013) analyzed the trajectory (i.e., the length and severity) of maternal depression that predicted the variations in child outcomes. In their meta-analysis, Goodman et al. (2011) stated that the clinical evaluation of depression is not necessarily better than a symptom report. They emphasized the importance of assessing the trajectory of maternal depression and the child's age at first exposure because depressive symptoms tend to vary over time and can have different effects on child behavioral problems, psychopathologies, or both. Therefore, medical conditions related to maternal depression were considered in most longitudinal studies.

Regarding the informants, eight studies used the mother as the sole source of information (Anhalt et al., 2007; Barker \& Maughan, 2009; Boyd \& Tervo-Clemmens, 2013; Gerkensmeyer, Perkins, Day, et al., 2011; Gerkensmeyer, Perkins, Scott, et al., 2008; Goosby, 2007; Mickelson \& Demmings, 2009; Zanca et al., 2013), and 13 studies did not specify the mothers' depression status at the time of data collection (Barker et al., 2012; Barker \& Maughan, 2009; Brown et al., 2013; Criss et al., 2009; Dubois-Comtois et al., 2013; Goosby, 2007; Hart et al., 2008; Heberle et al., 2014; Karevold et al., 2009; Lau et al., 2007; Lengua et al., 2008; Piché et al., 2011; Wang et al., 2013). Because depressive symptoms may affect the quality of mothers' reports, implying a potential methodological problem that limits the validity of the information provided, 18 studies employed multiple respondents including not only mothers but also children, fathers, and teachers, which increased the validity of the findings.

Another methodological issue worth discussing concerns the psychometric quality of the instruments used to assess social support. Thirteen studies (48.14\%) referred to validated instruments; however, a wide variety of methods were used, suggesting the absence of standard testing instruments, which would favor direct comparisons between the different findings. 
The studies analyzed in the present review most frequently addressed internalizing and externalizing behavioral problems assessed using the CBCL, which is widely used in the literature. Childhood depression was the most frequently addressed psychopathology (Goosby, 2007; Lau et al., 2007; Lengua et al., 2008), and this outcome was common among the children of mothers with depression (Mendes, Loureiro, Crippa, et al., 2012). This finding might indicate the transgenerational nature of depression.

Most studies examined boys and girls, and four studies performed gender comparisons. One of these studies revealed that girls have more internalizing problems and boys more externalizing problems (Ashman et al., 2008). Other studies verified different predictors of the behavioral problems shown by boys (i.e., fewer stressors) and girls (i.e., more maternal social support) (Barker \& Maughan, 2009). Karevold et al. (2009), for example, observed that social support was predictive of fewer internalizing problems for girls but not for boys. Only one out of four studies failed to find a gender effect (Wang et al., 2013).

The samples of five studies (Allen-Meares et al., 2010; Criss et al., 2009; Fatori et al., 2013; Goosby, 2007; Mickelson \& Demmings, 2009) were considered high risk because they were mostly composed of families with low socioeconomic status. These families might have introduced a pre-established condition of combined risks into the analysis.

Of the eight cross-sectional studies, only one did not find an association between social support and child behavioral problems, psychopathologies, or both (Piché et al., 2011). This study addressed symptoms of maternal depression and anxiety, focusing on punitive maternal care (including physical and/or sexual abuse). This variable was related to more externalizing problems, which emphasizes the presence of combined risks with regard to maternal depression and anxiety.

Regarding the study limitations, one of the five longitudinal correlational studies (Anhalt et al., 2007) examined perinatal maternal factors but did not assess whether a change occurred in the maternal depressive symptoms over the 7-year assessment period. Another study (Foster et al., 2008) had a brief follow-up period of only 3 months.

The longitudinal experimental studies also assessed a broad range of variables, which hindered the data comparison due to the diversity of the results. Overall, however, the analyzed studies found that fewer contextual risk factors predicted fewer behavioral problems and depressive symptoms in children (Ashman et al., 2008; Barker \& Maughan, 2009; Hart et al., 2008; Karevold et al., 2009; Lau et al., 2007; Lengua et al., 2008); more parental resources predicted fewer behavioral problems and psychopathologies (Allen-Meares et al., 2010; Criss et al., 2009; DuboisComtois et al., 2013; Goosby, 2007; Gross et al., 2009); more social support predicted fewer behavioral problems (Barker \& Maughan, 2009; Heberle et al., 2014; Karevold et al., 2009); and greater maternal harshness correlated with more externalizing problems (Wang et al., 2013).

The nine predictive studies that addressed the role of contextual risk factors concerning children's mental health included a variety of factors, which made direct comparisons across studies difficult. In general, however, they focused on the impact of cumulative risk in the presence of maternal depression and negative sociodemographic conditions, such as poverty and a risky neighborhood. The results suggested that the impact of maternal depression on children's mental health was stronger than other risk factors. The results also highlighted the beneficial impact of social support on the mental health of depressed mothers' children.

Two studies addressed biological variables: one study compared twin pairs (Lau et al., 2007), and another measured brain potentials (Ashman et al., 2008). The former study did not find an association between genetic risk and social support; the latter study identified a moderate correlation between frontal brain activity and contextual risk factors. Importantly, a study of genetic variables is necessary to better understand the effect of gene-environment interactions on child outcomes (Rutter, 2007).

\section{Conclusion}

Having analyzed the positive influence of social support revealed by the studies in the present review, identifying the sources of social support that minimize the effect of maternal depression on child outcomes can contribute to the development of prevention and intervention programs. In-school assessments of school-age children and parents who experience situations of significant stress or difficulty might identify at-risk individuals for guidance and specialized care referrals.

In addition, because pregnancy encourages the early identification of contextual risk factors, the inclusion of instruments that screen for depression as part of the prenatal care provided by the healthcare services would enable the prevention and treatment of maternal depressive symptoms to prevent behavioral and psychopathological problems in children.

Identifying social support sources can also encourage prevention and intervention strategies for children exposed to maternal depression; such strategies include institutional programs that offer athletic and artistic activities (among others) as sources of child social support.

Future research should assess the influences of social support on the outcomes in children who live with maternal depression to obtain a clearer operational definition of social support. This research should explicitly analyze the different types of social support and explore contextual risk and protective factors that interact with the various dimensions: instrumental, emotional, informational, tangible aid, positive social interaction, affection, and esteem. Furthermore, future studies should also analyze the trajectory of maternal depression to better understand the influence of social 
support regarding clinical variables such as the severity and chronicity of this disorder.

Although the present review systematically selected the articles, an exhaustive review was not conducted, and only a few papers were included that addressed a wide variety of variables, thereby limiting the data comparison and conclusions. Only three keywords were used to systematically search the databases. Although these keywords returned the greatest number of papers, other words could also have been used.

The present review contributes to discussing the practical and theoretical implications of the interplay between contextual risk factors and maternal depression. We synthetized and integrated findings on the impact of maternal depression and contextual factors (such as demographic variables, parental practices and family conflicts) on children's mental health, as well as the protective role of social support in this context. We anticipate that this review will be helpful in designing interventions for mental health promotion and prevention.

\section{References}

Allen-Meares, P., Blazevski, J., Bybee, D., \& Oyserman, D. (2010). Independent effects of paternal involvement and maternal mental illness on child outcomes. Social Service Review, 84(1), 103-127. doi:10.1086/652989

Anhalt, K., Telzrow, C. F., \& Brown, C. L. (2007). Maternal stress and emotional status during the perinatal period and childhood adjustment. School Psychology Quarterly, 22(1), 74-90. doi:10.1037/1045-3830.22.1.74

Ashman, S. B., Dawson, G., \& Panagiotides, H. (2008). Trajectories of maternal depression over 7 years: Relations with child psychophysiology and behavior and role of contextual risks. Development and Psychopathology, 20(1), 55-77. doi:10.1017/S0954579408000035

Barker, E. D., Copeland, W., Maughan, B., Jaffee S. R., \& Uher, R. (2012). Relative impact of maternal depression and associated risk factors on offspring psychopathology. The British Journal of Psychiatry, 200(2), 124-129. doi:10.1192/bjp.bp.111.092346

Barker, E. D., \& Maughan, B. (2009). Differentiating early-onset persistent versus childhood-limited conduct problem youth. The American Journal of Psychiatry, 166(8), 900-908. doi:10.1176/appi.ajp.2009.08121770

Boyd, R. C., \& Tervo-Clemmens, B. (2013). Exploring maternal and child effects of comorbid anxiety disorders among African American mothers with depression. Journal of Depression \& Anxiety, 2(129), 1000129. doi:10.4172/2167-1044.1000129

Brown, J., Barbarin, O., \& Scott, K. (2013). Socioemotional trajectories in black boys between kindergarten and the fifth grade: The role of cognitive skills and family in promoting resiliency. American Journal of Orthopsychiatry, 83(2-3), 176-184. doi:10.1111/ajop.12027
Campbell, S. B., Matestic, P., von Stauffenberg, C., Mohan, R., \& Kirchner, T. (2007). Trajectories of maternal depressive symptoms, maternal sensitivity, and children's functioning at school entry. Developmental Psychology, 43(5), 1202-1215. doi:10.1037/0012-1649.43.5.1202

Criss, M. M., Shaw, D. S., Moilanen, K. L., Hitchings, J. E., \& Ingoldsby, E. M. (2009). Family, neighborhood, and peer characteristics as predictors of child adjustment: A longitudinal analysis of additive and mediation models. Social Development, 18(3), 511-535. doi:10.1111/j.1467-9507.2008.00520.x

Dubois-Comtois, K., Moss, E., Cyr, C., \& Pascuzzo, K. (2013). Behavior problems in middle childhood: The predictive role of maternal distress, child attachment, and motherchild interactions. Journal of Abnormal Child Psychology, 41(8), 1311-1324. doi:10.1007/s10802-013-9764-6

Elgar, F. J., Mills, R. S. L., McGrath, P. J., Waschbusch, D. A., \& Brownridge, D. A. (2007). Maternal and paternal depressive symptoms and child maladjustment: The mediating role of parental behavior. Journal of Abnormal Child Psychology, 35(6), 943-955. doi:10.1007/s10802-007-9145-0

Fatori, D., Bordin, I. A., Curto, B. M., \& de Paula, C. S. (2013). Influence of psychosocial risk factors on the trajectory of mental health problems from childhood to adolescence: A longitudinal study. BMC Psychiatry, 13, 31. doi:10.1186/1471-244X-13-31

Foster, C. E., Webster, M. C., Weissman, M. M., Pilowsky, D. J., Wickramaratne, P. J., Talati, A., ... King, C. A. (2008). Remission of maternal depression: Relations to family functioning and youth internalizing and externalizing symptoms.Journal of ClinicalChild\&AdolescentPsychology, 37(4), 714-724. doi:10.1080/15374410802359726

Gerkensmeyer, J. E., Perkins, S. M., Day, J., Austin, J. K., Scott, E. L., \& Wu, J. (2011). Maternal depressive symptoms when caring for a child with mental health problems. Journal of Child and Family Studies, 20(5), 685-695. doi:10.1007/s10826-011-9445-4

Gerkensmeyer, J. E., Perkins, S. M., Scott, E. L., \& Wu, J. (2008). Depressive symptoms among primary caregivers of children with mental health needs: Mediating and moderating variables. Archives of Psychiatric Nursing, 22(3), 135-146. doi:10.1016/j.apnu.2007.06.016

Goodman, S. H., Rouse, M. H., Connel, A. M., Broth, M. R., Hall, C. M., \& Heyward, D. (2011). Maternal depression and child psychopathology: A meta-analytic review. Clinical Child and Family Psychology Review, 14(1), 1-27. doi:10.1007/s10567-010-0080-1

Goosby, B. J. (2007). Poverty duration, maternal psychological resources, and adolescent socioemotional outcomes. Journal of Family Issues, 28(8), 1113-1134. doi:10.1177/0192513X07300712

Gottlieb, B. H. (1983). Social support strategies: Guidelines for mental health practice. Beverly Hills, CA: Sage. 
Gross, H. E., Shaw, D. S., Burwell, R. A., \& Nagin, D. S. (2009). Transactional processes in child disruptive behavior and maternal depression: A longitudinal study from early childhood to adolescence. Development and Psychopathology, 21(1), 139-156. doi:10.1017/S0954579409000091

Hart, D., Atkins, R., \& Matsuba, M. K. (2008). The association of neighborhood poverty with personality change in childhood. Journal of Personality and Social Psychology, 94(6), 1048-1061. doi:10.1037/0022-3514.94.6.1048

Heberle, A. E., Krill, S. C., Briggs-Gowan, M. J., \& Carter, A. S. (2014). Predicting externalizing and internalizing behavior in kindergarten: Examining the buffering role of early social support. Journal of Clinical Child \& Adolescent Psychology. doi:10.1080/15374416.2014.886254

Karevold, E., Roysamb, E., Ystrom, E., \& Mathiesen, K. S. (2009). Predictors and pathways from infancy to symptoms of anxiety and depression in early adolescence. Developmental Psychology, 45(4), 1051-1060. doi:10.1037/a0016123

Lau, J. Y. F., Rijsdijk, F., Gregory, A. M., McGuffin, P., \& Eley, T. C. (2007). Pathways to childhood depressive symptoms: The role of social, cognitive, and genetic risk factors. Developmental Psychology, 43(6), 1402-1414. doi:10.1037/0012-1649.43.6.1402

Lengua, L. J., Bush, N. R., Long, A. C., Kovacs, E. A., \& Trancik, A. M. (2008). Effortful control as a moderator of the relation between contextual risk factors and growth in adjustment problems. Development and Psychopathology, 20(2), 509-528. doi:10.1017/S0954579408000254

Mendes, A. V., Loureiro, S. R., \& Crippa, J. A. S. (2008). Depressão materna e a saúde mental de escolares. Revista de Psiquiatria Clínica, 35(5), 178-186. doi:10.1590/S0101-60832008000500002

Mendes, A. V., Loureiro, S. R., Crippa, J. A. S., Gaya, C. M., García-Esteve, L., \& Martín-Santos, R. (2012). Mothers with depression, school-age children with depression? A systematic review. Perspectives in Psychiatric Care, 48(3), 138-148. doi:10.1111/j.1744-6163.2011.00318.x

Mickelson, K. D., \& Demmings, J. L. (2009). The impact of support network substitution on low-income women's health: Are minor children beneficial substitutes? Social Science \& Medicine, 68(1), 80-88. doi:10.1016/j.socscimed.2008.09.057

Parent, J., Jones, D. J., Forehand, R., Cuellar, J., \& Shoulberg, E. K. (2013). The role of coparents in African American single-mother families: The indirect effect of coparent identity on youth psychosocial adjustment. Journal of Family Psychology, 27(2), 252-262. doi:10.1037/a0031477

Piché, G., Bergeron, L., Cyr, M., \& Berthiaume, C. (2011). Interaction effects between maternal lifetime depressive/anxiety disorders and correlates of children's externalizing symptoms. Journal of Child and Family Studies, 20(5), 596-604. doi:10.1007/s10826-010-9433-0

Rhodes, K. V., \& Iwashyna, T. J. (2007). Child injury risks are close to home: Parent psychosocial factors associated with child safety. Maternal and Child Health Journal, 11(3), 269-275. doi:10.1007/s10995-006-0171-2
Rueger, S. Y., Malecki, C. K., \& Demaray, M. K. (2010). Relationship between multiple sources of perceived social support and psychological and academic adjustment in early adolescence: Comparisons across gender. Journal Youth Adolescence, 39(1), 47-61. doi:10.1007/s10964-008-9368-6

Rutter, M. (2007). Gene-environment interdependence. Developmental Science, 10(1), 12-18. doi:10.1111/ j.1467-7687.2007.00557.x

Wang, F., Christ, S. L., Milss-Koonce, W. R., Garrett-Peters, P., \& Cox, M. J. (2013). Association between maternal sensitivity and externalizing behavior from preschool to preadolescence. Journal of Applied Developmental Psychology, 34(2), 89-100. doi:10.1016/j.appdev.2012.11.003

Zanca, C. G., Pizeta, F. A., Osório, F. L., \& Loureiro, S. R. (2013). Percepção do apoio social de famílias que convivem com a depressão materna. Estudos de Psicologia (Natal), 18(2), 249-257. doi:10.1590/S1413-294X2013000200010

Ana Paula Casagrande Silva is a M.S. candidate in the Graduate Program in Mental Health of the Faculdade de Medicina de Ribeirão Preto at the Universidade de São Paulo.

Sonia Regina Loureiro is a Professor of the Faculdade de Medicina de Ribeirão Preto at the Universidade de São Paulo.

Received: Mar. 27, 2014

1st Revision: July 7, 2014 Approved: July 22, 2014

How to cite this article:

Silva, A. P. C., \& Loureiro, S. R. (2014). Analysis of studies on social support and children of depressed mothers: A systematic review. Paidéia (Ribeirão Preto), 24(59), 397-405. doi: 10.1590/1982-43272459201414 


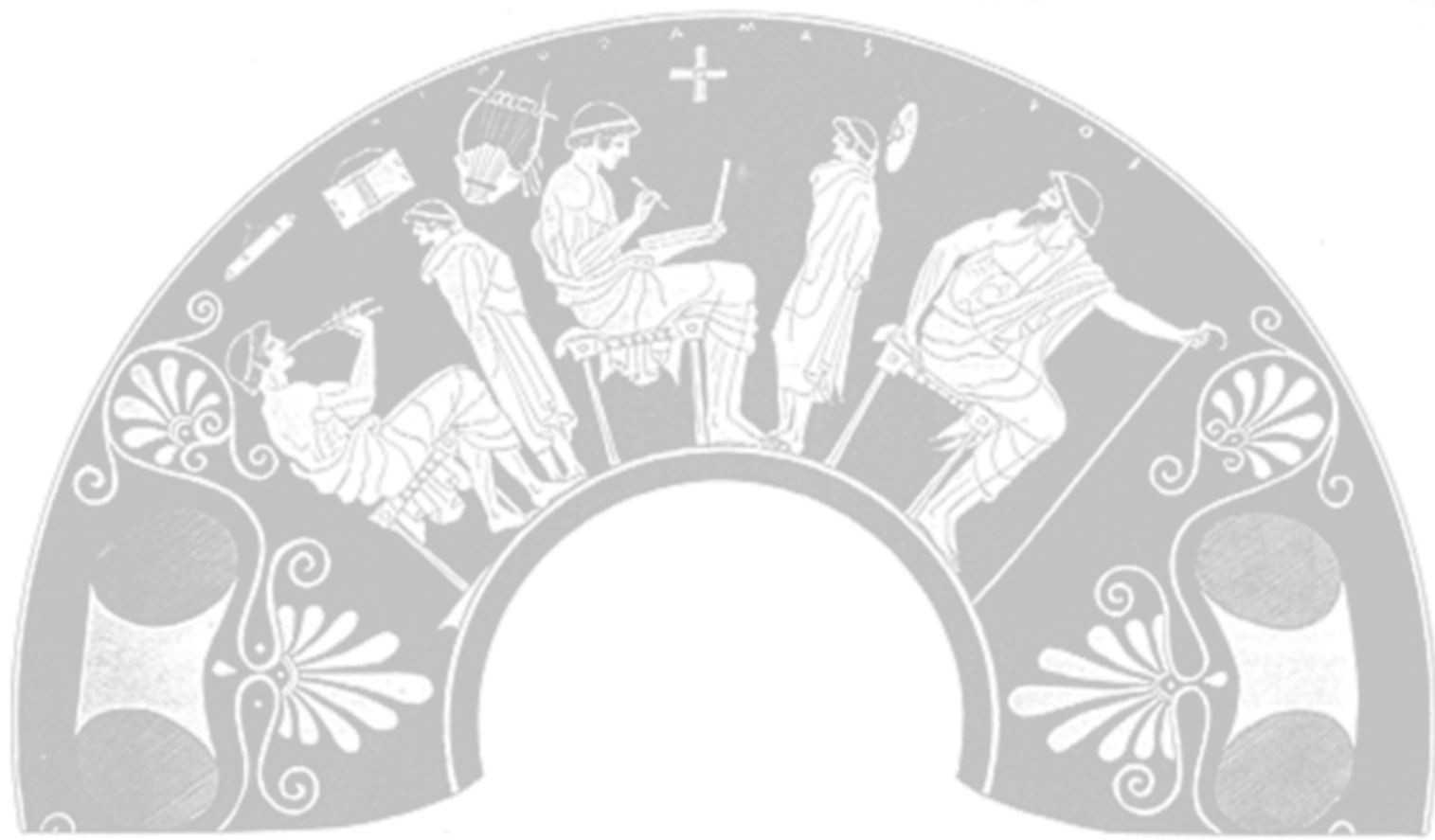

